\title{
INFLUENCE OF NITRIC OXIDE IN THE IMPROVEMENT OF MUSCLE POWER
}

\author{
Daniela Navarro D’Almeida Bernardo ${ }^{1}$, Flávio Fernandes Bryk ${ }^{2}$, Patricia Maria de Moraes Barros Fucs ${ }^{3}$
}

\begin{abstract}
Objective: To evaluate whether nitric oxide (NO) supplementation is directly related to increased muscle power in response to strength exercise training. Methods: The study included 36 individuals who underwent training for eight weeks (three times per week) with weights, who were randomly divided into two groups, both receiving the same training protocol, but one group used $3 \mathrm{~g}$ of arginine, as a precursor of $\mathrm{NO}$, and the other received placebo. Results: There was no significant difference between groups, only a significant difference for
\end{abstract}

both groups between moments: before and after the training protocol. Conclusion: Oral administration of arginine associated with a training program did not increase the muscular power of individuals. Level of Evidence I, Study Type: High quality randomized trial with statistically significant difference or no statistically significant difference but narrow confidence intervals.

Keywords: Nitric oxide. Exercise therapy. Muscle strength. Dietary supplements. Physical education and training.

Citation: D'Almeida Bernardo DN, Bryk FF, Fucs PMM. Influence of nitric oxide in the improvement of muscle power. Acta Ortop Bras. [online]. 2015;23(6):294-8. Available from URL: http://www.scielo.br/aob.

\section{INTRODUCTION}

Nitric oxide (NO) is one of the smallest and simplest molecules ever biosynthesized. ${ }^{1}$ It is a free radical in form of a colorless gas, with seven electrons of nitrogen and eight electrons of oxygen, with one unpaired electron. ${ }^{2}$

$\mathrm{NO}$ is an endogenous molecule involved in numerous physiological processes ranging from neurotransmission to modulation of the inflammatory state, acting in the aggregation, vasodilation and chemotaxis. NO also has bactericidal properties. ${ }^{3-5} \mathrm{NO}$ is one of the most important mediators of intra-and extracellular processes. ${ }^{6}$ Because it has a vasodilator function, $\mathrm{NO}$ acts in situations of muscle overload, stimulating the transition between the muscle fiber types. ${ }^{7}$

The NO produced by vascular endothelial cells is an important regulator of the vascular function. ${ }^{8}$ The production of NO in humans occurs when L-arginine is converted to L-citrulline, in a reaction catalyzed by the enzyme nitric oxide synthase (NOS). ${ }^{7}$ The NO produced by endothelial cells plays an essential role in the relaxation of the blood vessel. In pathophysiological conditions, vascular relaxation occurs when the membrane receptors of endothelial cells are activated by soluble stimulators or when there is an increase in the friction exerted by circulating cells on the endothelial layer, leading to activation of the enzyme e-NOS (endothelial NO synthase) present in these cells and consequent NO production. ${ }^{9}$ The e-NOS is strategically anchored to the endothelial cell membrane, which favors the presence of large amounts of NO near the muscle layer of the vessel and next to circulating blood cells. The NO produced in the endothelial cell diffuses rapidly into the muscle cells and to the vascular lumen. The rapid diffusion and the ease with which this molecule penetrates into other cells, thanks to its small size and its lipophilicity, are crucial to its biological roles. ${ }^{10}$

According to Cerqueira and Yoshida, ${ }^{11} \mathrm{NO}$ mediates several phenomena, such as endothelium-dependent vasorelaxation, platelet adhesion and aggregation, and baseline blood pressure regulation. In blood vessels, NO modulates vascular diameter and vascular resistance through its ability to relax the vascular smooth muscle.

Exercise training improves cardiovascular autonomic function and endothelial vasodilator systemically, promoting beneficial cardiac and vascular effects. These benefits may be also related to the increased production of NO. ${ }^{12}$

According to Flakoll et al., ${ }^{13}$ supplementation of arginine (with beta-hydroxy-beta-methylbutirate) improves contractile force by increasing muscle protein synthesis. For these authors, supplementation for long periods, concomitant with a resistance-training program, may be associated with improvement

All the authors declare that there is no potential conflict of interest referring to this article.

\footnotetext{
1. Centro Universitário Católico Salesiano - UniSALESIANO, Araçatuba, SP, Brazil.

2. Irmandade da Santa Casa de Misericórdia de São Paulo, São Paulo, SP, Brazil.

3. Faculdade de Ciências Médicas da Santa Casa de São Paulo (FCMSCSP), Department of Orthopedics and Traumatology, São Paulo, SP, Brazil.

Correspondence: Rua Tibiriçá, 1220 - ap. 304, bl. 07, Jardim América. 16071-000 Araçatuba, SP, Brazil. equilibrioconsultoria@hotmail.com
} 
of contractile force by increasing muscle protein synthesis. Apparently, the oral administration of the supplement provides better quality of training by three interrelated and interdependent mechanisms, triggered simultaneously by vasodilation: increased blood perfusion, facilitating the supply of oxygen and nutrients to the tissues, ${ }^{14,15}$ and greater glucose supply, with higher energy substrate for muscle contraction. ${ }^{16} \mathrm{Ac}$ cording to Angeli et al., ${ }^{7}$ the improved perfusion of skeletal muscle itself can contribute to a better quality of the resistance training, with increasing effects of training in muscle mass and in contractile power over time.

Definitions of strength and power are often contradictory and confusing. Nevertheless, according to the physics laws, strength or force $(F)$ is expressed as the product of mass and acceleration $(F[N]=m[k g])$. a $\left.\left[\mathrm{m} / \mathrm{s}^{2}\right]\right) .{ }^{17}$ Power $(P)$ represents the mechanical work under a variety of conditions, and it can be characterized as follows: $\left[P(W)=F(N) \times V\left(m \cdot s^{-1}\right)\right]$. Therefore, muscle power is highly dependent on the strength and both are important for sports performance and everyday activities. ${ }^{17}$ Angeli et al. ${ }^{7}$ found that, after two months of weight training, a group that received supplementation with arginine had significantly higher weight, lean mass and lower limb strength and significantly lower body fat percentage, while the control group showed no significant differences for the same period. As prolonged administration of arginine increases NO production, its supplementation has been associated with improved contractile function of the skeletal muscle.

There is a lack of information and studies on the effect of supplementation with $\mathrm{NO}$ and anaerobic exercises in the improvement of muscle power in humans.

The objective of the present study is to investigate the effects of supplementation with $\mathrm{NO}$ in muscle power after performing an exercise protocol for muscle strengthening. The hypothesis would be that such supplementation would lead to improve in muscle strength. Our goal is also to evaluate whether supplementation of arginine combined with muscle strengthening exercises is directly related to the increase of muscle power in horizontal and vertical jump functional tests.

\section{METHODS}

This is a randomized, placebo-controlled, double blind clinical trial. The study was performed at the Physical Therapy Rehabilitation Service of Santa Casa de Misericórdia de São Paulo, a university hospital, after approval by the local Research Ethics Committee, under number 267152. The study used a convenience sample of Physical Therapy graduated students. Every participant was informed about the research objectives and methods and signed a Free and Informed Consent forms for participation.

The study recruited all 44 graduate students in the Physical Therapy Department (20 men and 24 women) as volunteers. They were recruited personally in the classroom. They ought to be aged 20-30 years old to be included, performing no athletic activity, and without any pulmonary or cardiorespiratory disease. Exclusion criteria were: refusal to participate in examinations or in physical training sessions, refusal to receive or presenting gastrointestinal problems preventing the administration of placebo or the NO precursor arginine (orally administrated), presence of fractures, recent surgical treatment, orthopedic dise- ase in the last six months and history of cardiovascular disease (participants were asked about any heart disease, hypotension episodes or hypertension diagnosis or current treatment, as these would also constitute exclusion criteria).

We registered demographic data such as name, age and contact phone number. All participants were weighed and measured for height in a recently calibrated scale with maximum weight of $150 \mathrm{~kg}$ and maximum height of $2.20 \mathrm{~m}$.

Of the 44 regular students in the Department, 36 (16 women and 20 men) participated in the study with full documentations and were present in all examinations. All subjects had no history of physical activity prior to the study. Participants were aged 21-30 years old (mean 23.97 years old, standard deviation, SD, 2.38 years old), and body weight between 46 and $135 \mathrm{~kg}$ (mean $72.90 \mathrm{~kg}$, SD 17.69), height between 145 and $184 \mathrm{~cm}$ (average $1.66 \mathrm{~m}, \mathrm{SD} 0.09$ ) and body mass index (BMI) between 18.53 and $42.13 \mathrm{~kg} / \mathrm{m}^{2}$ (average $25.87 \mathrm{~kg} / \mathrm{m}^{2}$, SD 4,59).

The subjects were divided into two groups, both participating in the exercising protocol; the study group receiving arginine supplementation (that we called "the NO group") and the control group (CG) receiving maltodextrin, as a placebo. Maltodextrin is a complex carbohydrate derived from the hydrolysis of corn, which does not interfere with the study results, since the amount of maltodextrin was not sufficient to optimize the workout performance. Both arginine and placebo were produced by the same laboratory (Athlética Laboratório ADS). Arginine and placebo were orally administrated in equal capsules, both in the amount of $0.5 \mathrm{~g} / \mathrm{capsule.} \mathrm{A} \mathrm{total} \mathrm{of} \mathrm{six} \mathrm{capsules} \mathrm{per} \mathrm{training} \mathrm{day} \mathrm{was} \mathrm{gi-}$ ven to the participants, totaling $3 \mathrm{~g}$ of arginine or placebo, which was administered 45 minutes before training, with a previous period of one hour fasting for better effects.

One researcher (FFB) was responsible for the randomization, which was conducted by using sealed opaque envelopes. Allocation of participants was hidden from the other researchers and from trial participants.

\section{Assessment Protocol}

Muscle power was assessed twice in the study: the first protocol before muscle strengthening exercising protocol (M1), and the second eight weeks after the beginning of the exercising protocol (M2). In order to evaluate the effects of supplementation, the groups underwent two functional tests; the first was the single hop test, ${ }^{18}$ which is used to assess the muscle power of the lower limbs. This test consists of jumping forward with one leg, hands behind the back, reaching the maximum distance, which was registered. The test was performed twice with the dominant and the non dominant leg, the first for the participant to understand and adjust the movement and the second for analysis.

The second functional test, the vertical jump, ${ }^{18}$ aims to measure the power of the lower limbs in the vertical plane. The participant stands beside a wall, keeping the soles of his feet in contact with the ground. The test consists of jumping as high as possible, flexing the legs and swinging arms, if necessary, to perform the jump. The highest point reached is marked on the wall and height is measured. The test was performed twice: the first jump for the participant to understand the movement and the second jump for analysis.

The distance and height obtained with the single hop and the 
vertical jump tests were normalized by the height of each individual by the formula:

Test distance or height/individual height x 100 .

\section{Training protocol}

The training protocol was composed of exercises three times a week totaling 24 sessions, as described in Table 1. The total time for performing the training protocol was $30 \mathrm{~min}$, with an interval of rest between sessions of $1 \mathrm{~min}$. The load set for muscle strengthening was: starting the exercises without weight and increasing $1 \mathrm{~kg}$ every two weeks in a row, except knee extension, in which $70 \%$ of the maximum resistance (MR) was used. Aiming to reduce the margin of error of the exercise protocol, strategies were adopted for accurate understanding of the movements by participants, such as: standardized instructions were provided before performing the exercises, so that the participant was aware of the routine involved, the participant was instructed on the technique of the exercise; the evaluator was watchful for the body positioning by the participant, because small variations in the positioning of the joints involved in the movement could result in the use of other muscles in the task, leading to wrong interpretations of study results.

The exercises of the training protocol aimed at strengthening the abductor and adductor muscles of the hip, knee flexors and extensors and foot plantar flexors are shown in Figures 1 to 6. Four sets of 10 repetitions of each exercise were performed.

Table 1. Training program (exercising 3 times per week for 2 months, with 8 weeks of training in total).

\begin{tabular}{|c|c|c|c|c|}
\hline Exercise & Reps & Series & Load & Comments \\
\hline Abduction $10^{\circ}$ & 10 rep. & $4 x$ & $0-3 \mathrm{~kg}$ & $\begin{array}{c}\text { Increasing every } 2 \text { weeks } 1 \\
\mathrm{~kg} \text {, starting without load }\end{array}$ \\
\hline Adduction & 10 rep. & $4 x$ & $0-3 \mathrm{~kg}$ & $\begin{array}{c}\text { Increasing every } 2 \text { weeks } 1 \\
\mathrm{~kg} \text {, starting without load }\end{array}$ \\
\hline Unipodal calf & 10 rep. & $4 x$ & Place + step & $\begin{array}{l}\text { Performed on the ground } \\
\text { and on the step }\end{array}$ \\
\hline Bipedal calf & 10 rep. & $4 x$ & Step & 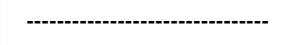 \\
\hline Isquiotibial & 10 rep. & $4 x$ & $1-4 \mathrm{~kg}$ & $\begin{array}{c}\text { Increasing every } 2 \text { weeks } 1 \\
\mathrm{~kg} \text {, starting without load }\end{array}$ \\
\hline Extensor $(70 \% \mathrm{HR})$ & 10 rep. & $4 x$ & -.---- & - \\
\hline
\end{tabular}

\section{Statistical analysis}

All data were recorded in Microsoft Office Excel 2007 sheets, and copied to the program SPSS version 20.0, used for statistical analysis. To compare the two groups with regard to the homogeneity of data such as body weight, height, body mass index (BMI) and age at the beginning of the study, we used the analysis of variance (ANOVA) test of independent measurements. For intra groups comparisons at the beginning and end of the intervention and inter groups comparisons after the intervention, ANOVA test for repeated measures was used. The initial calculation of the sample was based on the comparison of means using as reference similar studies, considering mean differences of 1.5 and standard deviation of 2 , with the level of significance of $5 \%$ and a statistical power of $80 \%$.

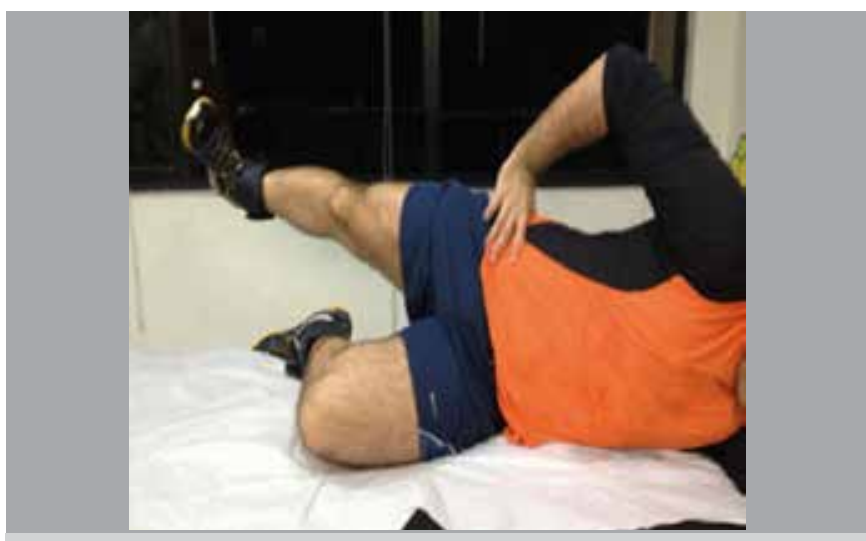

Figure 1. Abduction

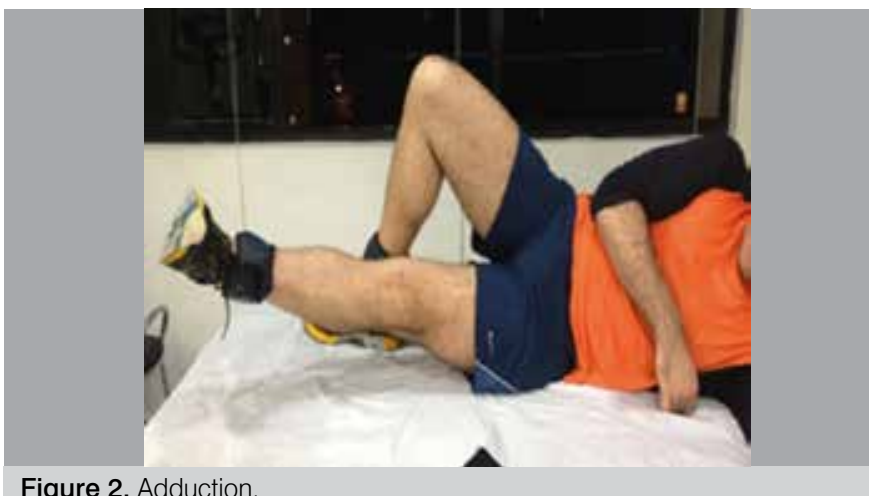

Figure 2. Adduction.

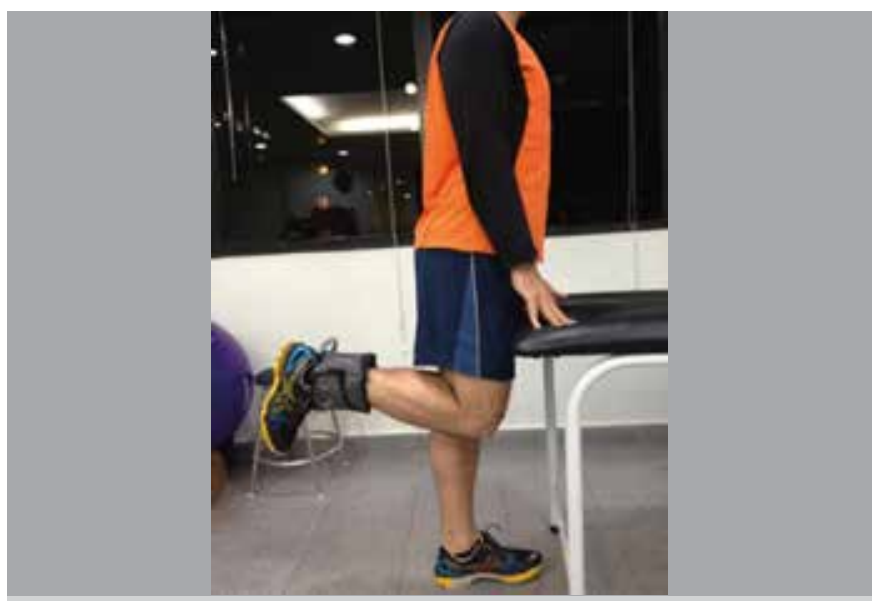

Figure 3. Knee flexion.

\section{RESULTS}

Table 2 shows that there was no significant difference in age, weight and BMI at baseline, but there was a statistical difference in the sample in height, with the group receiving arginine performing a greater height than the placebo group.

In the single hop test, normalized by height, there was a significant difference inside the groups comparing baseline and final values, but there was no significant difference between groups, according to Table 2.

For the vertical jump test, there was also a significant difference comparing baseline and final values, but there were no significant differences between groups, according to Table 2 . 


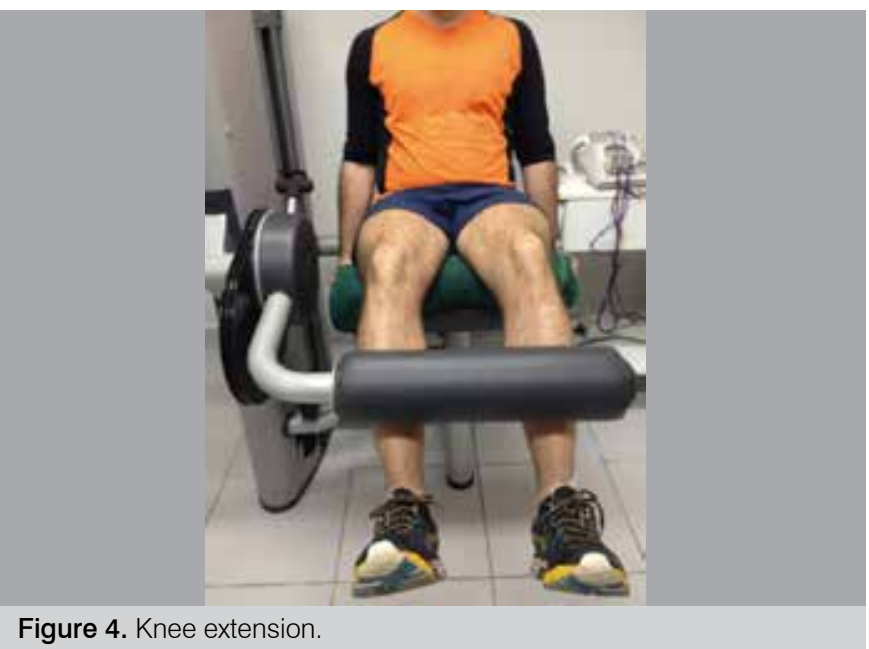

Figure 4. Knee extension.

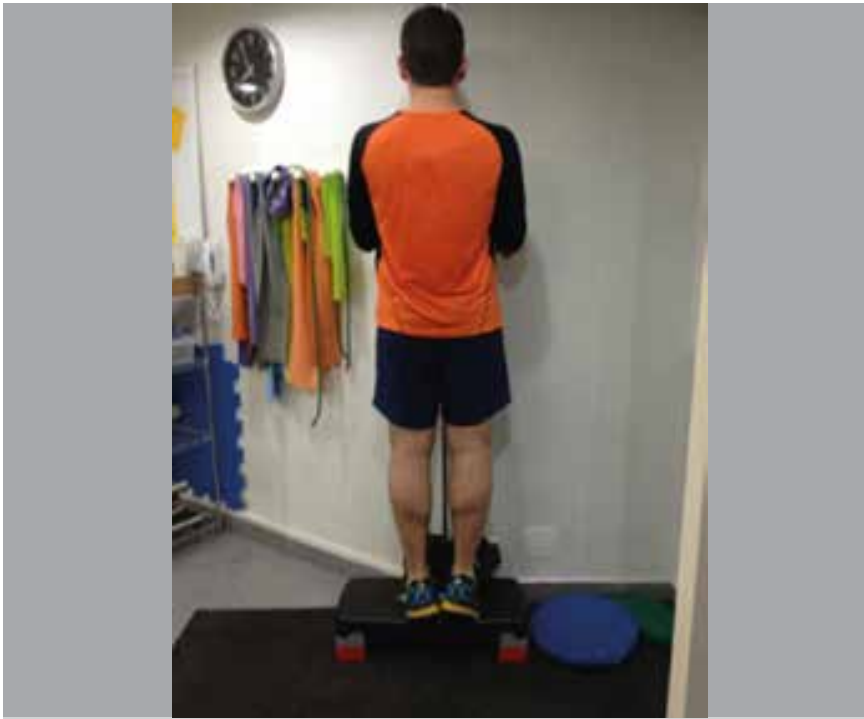

Figure 5. Bipodal calf.

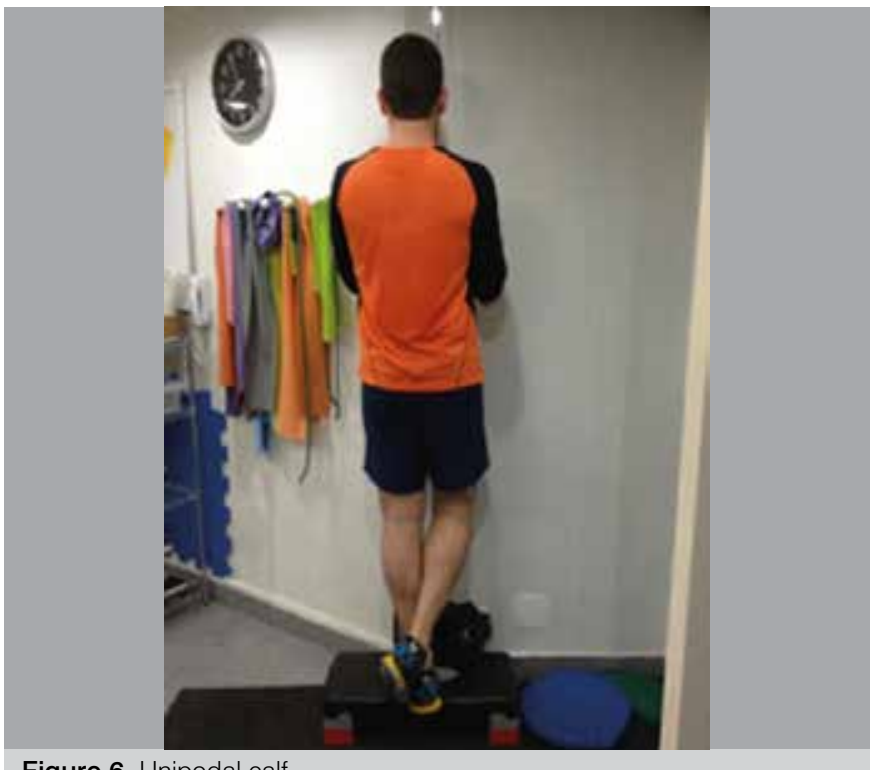

Figure 6. Unipodal calf.
Table 2. Mean and standard deviation of baseline values for age, height, body weight and body mass index (BMI) and for the study results of height normalized single hop test and height normalized standard vertical jump for the groups receiving nitric oxide supplementation (NO) and the control group (CG).

\begin{tabular}{|c|c|c|c|c|}
\hline \multicolumn{2}{|c|}{ Variables } & NO & CG & $p$ values \\
\hline \multicolumn{2}{|c|}{ Age (years old) } & $24.45 \pm 2.50$ & $23.37 \pm 2.15$ & 0.183 \\
\hline \multicolumn{2}{|c|}{ Height $(m)^{\star}$} & $1.70 \pm 0.07^{\star}$ & $1.61 \pm 0.10^{*}$ & 0.005 \\
\hline \multicolumn{2}{|c|}{ Body weight (kg) } & $75.49 \pm 12.91$ & $69.67 \pm 22.34$ & 0.334 \\
\hline \multicolumn{2}{|c|}{$\mathrm{BMI}(\mathrm{kg} / \mathrm{m})$} & $25.64 \pm 3.32$ & $26.16 \pm 5.91$ & 0.742 \\
\hline & HT.N M1 x Alt & HT.N M2 x Alt & Intra G & Inter G \\
\hline NO & $73.99 \pm 11.09$ & $78.70 \pm 11.43$ & $p=0.0001$ & $p=0.314$ \\
\hline \multirow[t]{2}{*}{$C G$} & $68.93 \pm 17.88$ & $76.30 \pm 16.38$ & & \\
\hline & SV.N M1 x Alt & SV.N M2 x Alt & Intra G & Inter G \\
\hline NO & $149.27 \pm 7.02$ & $150.64 \pm 7.27$ & $p=0.014$ & $p=0.55$ \\
\hline$C G$ & $148.23 \pm 7.50$ & $149.09 \pm 7.16$ & & \\
\hline
\end{tabular}

*Statistically significant difference, $\mathrm{p} \leq 0.05$; HT.N M1 $\times$ Alt: height normalized single hop test value at baseline; HT.N M2 x Alt: height normalized single hop test value at the final moment; SV.N M1 x Alt; height normalized standard vertical jump at baseline; SV.N M2 x Alt; height normalized standard vertical jump at the final moment.

\section{DISCUSSION}

The literature has shown that muscle strength and power are essential both for physical performance and for health. ${ }^{17,19,20}$ For sports training, muscle power is one of the most important variables. ${ }^{21,22}$ This is also true for everyday activities, in which the muscle power plays an important role. ${ }^{17,19}$

Among the several studies about $\mathrm{NO}$ and muscle mass and strength gains, the study by Angeli et al. ${ }^{7}$ stands out. The authors concluded that oral administration of $3 \mathrm{~g} /$ day of a $\mathrm{NO}$ precursor potentiates the effects of weight training, providing greater strength gains and muscle mass; however, the association of supplementation and exercise for a possible improvement of muscle power is not elucidated in the literature, there are no studies proving that using the supplement leads to the increase of muscular power. Since the variable power is directly proportional to the variable strength and speed, if there is an improvement in muscle strength, consequently we should expect improvements in muscle power.

In order to evaluate the improvement of muscle power, studies have used specific tests, such as the vertical jump and single hop test. ${ }^{23-25}$ According to Hespanhol et al.,. ${ }^{23}$ peak muscle power, average power and fatigue index are reliable measures with regard to repeated measures in assessing the vertical jump test. Among other methods designed to provide information on muscle function, there is the single hop test described by Daniel et al., ${ }^{18}$ which evaluates the components of strength and power. For the stability of a damaged muscle segment, the method of Selistre et al. ${ }^{26}$ was added. This method has well-established advantages, such as low cost, easy application, good reliability and validity. ${ }^{27-29}$ The distance measured in the jumps of the functional tests was normalized with the participant height to demonstrate that there is no significant difference between the groups, even considering that the participants in one group were higher than the others', as shown in Table 2. One limitation of this study was that there was the difference in height between groups, a fact that could influence the distance and height found the single hop test and vertical jump, respectively. However, the results were normalized by the height of each participant, minimizing, thus this bias. 
In the present study, there was no significant difference between groups, but there was a significant difference in both groups comparing baseline and final evaluation. Based on the results obtained, with the difference between the two moments, it is possible to say that the supplementation of arginine, as a precursor of NO, was not effective for improving muscle power, but it was able to improve muscle strengthening exercising. Unfortunately, there are no literature data that could be compared with the findings of this research, since the great majority of studies report the cardioprotective and vasodilators effects of $\mathrm{NO}$, as well as improvements in muscle strength and lean body mass.

Regarding the association of strength, muscle mass and muscle power, what differentiates strengthening exercises and strength and muscle power is the rate of speed for the execution of the movement. ${ }^{30-32}$ Force is usually related to work involving heavy loads, without the need of imposing high-speed movement. Power, on the other hand, has already been associated with loads below those recommended for strength, being more closely related to the speed of movement than to the load itself. ${ }^{32}$ There are two variables in the equation to obtain the calculation of muscle power, strength and speed. In this study, the force ratio was the variable recommended for the training protocol, since there are studies emphasizing the improvement of muscle strength using the NO precursor, ${ }^{15,16}$ but speed ratio was not used in this protocol, and this could have been the reason for not improving muscle power between the groups. Therefore, the question about the effects of the combination of NO precursor and muscle power has still to be investigated in the future.

A limitation of this study was the use of single hop and vertical jump tests. Single hop was designed to assess knee stability, and we believe that it might proxy performance, because an unstable knee could theoretically indicate a weak muscle in that limb. Vertical jump is used to assess muscle power. However, since the studies in the literature that address muscle strength use these tests, and in order to provide homogeneous data for comparison, we opted to use them as well.

\section{CONCLUSION}

Supplementation of arginine ( $3 \mathrm{~g} /$ training day) in healthy individuals after performing muscle strengthening exercises did not improve muscle power.

\section{REFERENCES}

1. Morris SM Jr, Billiar TR. New insights into the regulation of inducible nitric oxide synthesis. Am J Physiol. 1994;266(6 Pt 1):E829-39.

2. Beckman JS, KoppeONI WH. Nitric oxide, superoxide, and peroxinitrite: the good, the bad, and the ugly. Am J Physiol. 1996;271(5 Pt 1):C1424-37.

3. Katzung BG. Farmacologia básica e clínica. Rio de Janeiro: Guanabara Koogan; 2006

4. Saha RN, Pahan K. Signals for the induction of nitric oxide synthase in astrocytes. Neurochem Int. 2006;49(2):154-63.

5. Yuan Z, Feng W, Hong J, Zheng Q, Shuai J, Ge Y. p38MAPK and ERK promote nitric oxide production in cultured human retinal pigmented epithelial cells induced by high concentration glucose. Nitric Oxide. 2009;20(1):9-15.

6. Dusse LMS, Vieira LM, Carvalho MG. Revisão sobre óxido nítrico. J Bras Patol Med Lab. 2003;39(4):343-50.

7. Angeli G, Barros TL, Barros DFL, Lima M. Investigação dos efeitos da suplementação oral de arginina ON aumento de força e massa muscular. Rev Bras Med Esporte. 2007;13(2):129-32

8. Furchgott RF, Zawadki JV. The obligatory role of endothelial cells in the relaxation of arterial smooth muscle by acetylcholine. Nature. 1980;288(5789):373-6.

9. Busconi L, Michel T. Endothelial nitric oxide syntase. N-terminal myristoylation determines subcellular localization. J Biol Chem. 1993;268(12):8410-3.

10. Moncada S, Palmer RM, Higgs EA. Nitric oxide: physiology, pathophysiology, and pharmacology. Pharmacol Rev. 1991;43(2):109-42.

11. Cerqueira NF, Yoshida WB. Óxido nítrico: revisão. Acta Cir Bras. 2002;17(6):417-23.

12. Maiorana A, O'Driscoll G, Taylor R, Green D. Exercise and the nitric oxide vasodilator system. Sports Med. 2003;33(14):1013-35.

13. Flakoll P, Sharp R, Baier S, Levenhagen D, Carr C, Nissen S. Effect of beta-hydroxy-methylbutyrate, arginine, and lysine supplementation on strength, functionality, body composition, and protein metabolism in elderly women. Nutrition. 2004;20(5):445-51.

14. Meneilly GS, Battistini B, Floras JS. Contrasting effects of L-arginine on insulin-mediated blood flow and glucose disposal in the elderly. Metabolism. 2001;50(2):194-9.

15. Rådegran G, Saltin B. Nitric oxide in the regulation of vasomotor tone in human skeletal muscle. Am J Physiol. 1999;276(6 Pt 2):H1951-60.

16. Meneilly GS, Elliott T, Battistini B, Floras JS. N(G)-moONmethyl-L-arginine alters insulin-mediated calf blood flow but ONt glucose dispodal in the elderly. Metabolism. 2001;50(3):306-10.

17. Thompson CJ, Bembem MG. Reliability and comparability of the accelerometer as a measure of muscular power. Med Sci Sports Exerc. 1999;31(6):897-902.

18. Daniel D, Malcom L, Stone ML, Perth H, Morgan J, Riehi B. Quantification oh knee stability and function. Contemp Orthop. 1982;5:83-91.

19. Friedrich MJ. Women, exercise, and aging: strong message for the "weaker" sex. JAMA. 2001;285(11):1429-31.

20. Foldvari M, Clark M, Laviolette LC, Bernstein MA, Kaliton D, Castaneda C, et al Association of muscle power with functional status in community-dwelling elderly women. J Gerontol A Biol Sci Med Sci. 2000;55(4):M192-9.

21. Kraemer WJ, Fleck SJ, Evans WJ. Strength and power training: physiological mechanisms of adaptation. Exerc Sport Sci Rev.1996;24:363-97.

22. Kanehisa $\mathrm{H}$, Miyashita M. Specificity of velocity in strength training. Eur J Appl Physiol Occup Physiol. 1983;52(1):104-6.

23. Hespanhol JE, Silva Neto LG, Arruda M. Confiabilidade do teste de salto vertical com 4 séries de 15 segundos. Rev Bras Med Esporte. 2006;12(2):95-8.

24. Marchetti PH, Uchida MC. Influência da fadiga unilateral de membro inferior sobre o salto vertical bilatera. Rev Bras Med Esporte. 2011;17(6):405-8.

25. Simão R, Monteiro WD, Araújo CGS. Potência muscular máxima na flexão do cotovelo uni e bilateral. Rev Bras Med Esporte. 2001;7(5):157-62.

26. Selistre LFA, Cintra GC, Aleixo Junior RD, Rosa SMM. Relação entre torque extensor e relação I: $Q$ com salto unipodal triplo horizontal em jogadores profissionais de futebol. Rev Bras Med Esporte. 2012;18(6):390-3.

27. Sekir U, Yildiz Y, Hazneci B, Ors F, Saka T, Aydin T. Reliability of a functional test battery evaluating functionatility, proprioception, and strength in recreational athletes with functional ankle instability. Eur J Phys Rehabil Med 2008;44(4):407-15.

28. Reid A, Birmingham TB, Stratford PW, Alcock GK, Giffin JR. Hop testing provides a reliable and valid outcome measure during rehabilitation after anterior cruciate ligament reconstruction. Phys Ther. 2007;87(3):337-49.

29. Hamilton RT, Shultz SJ, Schmitz RJ, Perrin DH. Triple-hop distance as a valid predictor of lower limb strength and power. J Athl Train. 2008;43(2):144-51.

30. Goldspink G, Harridge S. Cellular and molecular aspects of adaptation in skeletal muscle. In: Komi PV, editor. Strength and power in sports. Oxford: Blackwell Science; 2003. p. 231-51.

31. Häkkinen K, Komi PV, Alén M. Effect of explosive type strength training on isometric force- and relaxation-time, electromyographic and muscle fibre characteristics of leg extensor muscle. Acta Physiol Scand. 1985;125(4):587-600.

32. Maud PJ. Aerobic and Anaerobic Power. In: Maud PJ, Foster C. Physiological assessment of human fitness. 2nd. Champaign: Human Kinetics; 1995. p. 115-32. 